\title{
Effect of exogenous melatonin on neuroendocrine-reproductive function of middle-aged female rats
}

\author{
E. Díaz1 , C. Fernández ${ }^{1}$, P. O. Castrillón' ${ }^{2}$, A. I. Esquifino ${ }^{2}$, B. Marín ${ }^{1}$ and B. Díaz López ${ }^{1 *}$ \\ ${ }^{1}$ Dpto Biología Funcional, Area Fisiologia, Facultad de Medicina, Universidad de Oviedo, C/Julian Claveria, N6, 33006, Oviedo, Spain; \\ and 'Dpto Bioquímica y Biología Molecular III, Universidad Complutense, Madrid, Spain
}

\begin{abstract}
The possible role of melatonin in the regulation of the reproductive system of female rats during ageing was investigated in middle-aged female rats showing irregular duration of the oestrous cycle $(n=30)$. Blood samples were obtained by jugular venepuncture during the oestrous cycle in control rats. After this experiment was completed, the female rats were treated with melatonin for 2 months and blood samples were obtained at different stages of the oestrous cycle. Plasma LH, FSH and prolactin concentrations were significantly increased in the afternoon of the day of pro-oestrus after melatonin treatment compared with control rats. Moreover, FSH concentrations too were significantly increased on the morning of pro-oestrus and oestrus in melatonin treated rats compared with control rats. Similarly, oestradiol concentrations were significantly higher on the morning of pro-oestrus in melatonin treated rats compared with controls. Another group of rats showing irregular duration of the oestrous cycle was used to study the possible effect of melatonin treatment on the timing of prooestrous surges of LH and FSH. The results showed that LH and FSH peak values occurred at $5 \mathrm{~h}$ after melatonin treatment. Pituitary responsiveness to LHRH in a $90 \mathrm{~min}$ test was also studied in middle-aged rats showing irregular duration of the oestrous cycle that had been injected for 1 month with either melatonin or saline. Prolactin response was unaffected by exogenous melatonin, but a stimulatory effect of melatonin on $\mathrm{LH}$ and FSH pituitary responsiveness to LHRH was observed. The results indicate an improved function of the neuroendocrine-reproductive axis in middle-aged rats after melatonin treatment.
\end{abstract}

\section{Introduction}

The pineal gland is involved in animal and human reproduction through the action of its hormone, melatonin. Prolonged and quantitatively increased circulating melatonin concentrations have been observed in association with amenorrhoea (Berga et al., 1988; Laughlin et al., 1991) and decreased fertility in women (Kauppila et al., 1987). Exogenous melatonin administration alone or in combination with a synthetic progestin caused a significant decrease in $\mathrm{LH}$, oestradiol and progesterone in women, and consequently this combination was shown to be an effective oral contraceptive (Voordouw et al., 1992). Exogenous melatonin administration at doses resulting in increased concentrations of melatonin for at least $8 \mathrm{~h}$, increased LH concentrations and $\mathrm{LH}$ pulse amplitude during the follicular, but not the luteal, phase of the menstrual cycle (Cagnacci et al., 1995). Studies in rats indicate that melatonin might be important in the timing of the LH surge (that is, in the afternoon of the day of pro-oestrus) (Chiba et al., 1994), although high doses of melatonin given over the critical

*Correspondence.

Resubmitted manuscript received 4 March 1999. period can block the LH surge (Ying and Greep, 1973; Rivest et al., 1985). These opposing effects may be explained by the age at which the observations were made; in general it appears that melatonin is inhibitory in young fertile subjects and has a stimulatory effect with increasing age.

It has been suggested that melatonin may also be involved in ageing (Reiter, 1992). Melatonin is produced and secreted into the blood in a circadian rhythm; maximum production occurs during the dark phase of the day. The $24 \mathrm{~h}$ rhythm of melatonin production is very robust in young animals, but this circadian rhythm deteriorates with age. Thus, in old animals, the amount of melatonin secreted is lower than in young individuals and the administration of melatonin may be beneficial in delaying age-related degenerative conditions (Reiter, 1994). Long-term melatonin treatment in rats can postpone the age-related decrease in survival rates, circulating sex steroids and ${ }^{125}$ I-labelled melatonin binding sites in the brain (Oaknin-Bendahan et al., 1995).

Alterations in LH surges become apparent in middle-aged rats (Harney et al., 1996). Lambalk et al. (1997) postulated that post-menopausal ageing has a major suppressive effect on the function of pituitary gonadotrophes. In addition, the study of Arias et al. (1996) supports the hypothesis that a 
decrease in the excitatory inputs to LHRH neurones may be involved directly in the reduction of the activity of the hypothalamic-pituitary-ovarian axis observed during ageing. However, it is not known to what extent the hypothalamus and pituitary are involved in this process. The aim of the present study was to investigate the possible role of melatonin in the regulation of the reproductive system in ageing female rats at both the hypothalamus and the pituitary.

\section{Materials and Methods}

A total of 30 control female Wistar rats (11-month-old) from our colony were used. Animals were housed under a $12 \mathrm{~h}$ light: $12 \mathrm{~h}$ dark photoperiod (lights on at 08:00 h) at a temperature of approximately $23^{\circ} \mathrm{C}$. Standard rat chow and tap water were available ad libitum. Vaginal smears were taken from animals between 10:00 $\mathrm{h}$ and 11:30 $\mathrm{h}$ for 15 days to select rats showing irregular duration (that is $>5$ days) of the oestrous cycle. In these animals the duration of the oestrous cycle ranged from 6 to $>10$ days. None of the female rats studied showed conditions such as persistent oestrus or recurrent pseudopregnancy. Vaginal smears were also taken from the animals after melatonin treatment.

\section{Plasma concentrations of gonadotrophins, prolactin and oestradiol throughout the oestrous cycle before and after melatonin treatment}

After the first experiment involving vaginal smears was completed, blood samples at different stages of the oestrous cycle were randomly obtained from all female rats by jugular venepuncture under ether anaesthesia. In this first stage of the experiment, the rats were considered as the control group. Blood samples $(1 \mathrm{ml})$ were collected between 11:00 h and 12:00 $\mathrm{h}$ for dioestrus $(n=28)$, pro-oestrus a.m. $(n=28)$, oestrus $(n=27)$ and metoestrus $(n=22)$ and between $17: 00 \mathrm{~h}$ and $17: 30 \mathrm{~h}$ for pro-oestrus p.m. $(n=28)$. After this stage of the experiment was completed, the animals were treated with melatonin and were considered as the experimental group. Melatonin (M-5250, Sigma Chemical Co, St Louis, MO) was dissolved in a small volume of absolute ethanol and diluted in $0.9 \%(\mathrm{w} / \mathrm{v}) \mathrm{NaCl}$. A dose of $150 \mu \mathrm{g}$ melatonin per $100 \mathrm{~g}$ body weight was administered s.c. once a day at the end of the light phase (18:30-19:00 h) for 2 months to 11-months-old female rats showing irregular duration of the oestrous cycle. After the melatonin treatment, blood samples were obtained at different stages of the oestrous cycle: dioestrus $(n=17)$, pro-oestrus a.m. $(n=13)$, oestrus $(n=13)$, metoestrus $(n=13)$ and pro-oestrus p.m. $(n=12)$. Melatonin treatment was continued until blood sample collections were completed. Blood sampling was carried out using the same procedure described above. The duration of the oestrous cycle after melatonin treatment was between 4 and 9 days. The blood samples were centrifuged and plasma was stored at $-20^{\circ} \mathrm{C}$ until assays for $\mathrm{LH}, \mathrm{FSH}$, prolactin and oestradiol were conducted.

\section{Plasma concentrations of gonadotrophins on the day of pro-oestrus}

A different group of 11- to 15-month-old control rats $(n=$ 50) showing irregular duration of the oestrous cycle was used to study the effects of melatonin treatment on the timing of LH and FSH surges on the day of pro-oestrus. The pro-oestrous stage of the oestrous cycle was confirmed by vaginal smears. Serial blood samples $(1 \mathrm{ml})$ were taken at 07:00 h $(n=8), 10: 00 \mathrm{~h}(n=7), 14: 00 \mathrm{~h}(n=10), 17: 00 \mathrm{~h}(n=$ $20), 21: 00 \mathrm{~h}(n=9)$ and $01: 00 \mathrm{~h}(n=10)$ using the procedure described earlier. After this stage of the experiment was completed, the animals were treated with melatonin $(150 \mu \mathrm{g}$ per $100 \mathrm{~g}$ body weight) for 2 months, after which serial blood samples were taken at the same time points $(07: 00 \mathrm{~h}(n=6)$, 10:00 h $(n=5), 14: 00 \mathrm{~h}(n=6), 17: 00 \mathrm{~h}(n=18), 21: 00 \mathrm{~h}(n=8)$, 01:00 h $(n=5))$ using the procedure described earlier. Blood samples were processed as in the first experiment.

\section{Pituitary responsiveness to LHRH}

The effect of chronic administration of melatonin on pituitary gonadotrophins and prolactin responsiveness to LHRH was tested in 12-month-old female rats showing irregular duration of the oestrous cycle. Animals were randomly assigned to two groups: control $(n=12)$ and melatonin treated $(150 \mu \mathrm{g}$ per $100 \mathrm{~g}$ body weight) $(n=21)$. The control group received $10 \%$ ethanol-90\% saline. Animals were treated for 1 month, after which the first dioestrus was detected by vaginal smears performed at 16:00 h. After detection of the first dioestrus, an LHRH test was performed between 16:00 h and 18:00 h. Pituitary responsiveness to a bolus injection of LHRH was tested by taking a basal sample and subsequently injecting animals i.v. with LHRH (50 ng LHRH per $100 \mathrm{~g}$ body weight) (Sigma) diluted in saline. Injected volumes ranged from 0.05 to $0.1 \mathrm{ml}$. Additional blood samples were obtained at 15,30,60 and 90 min after the LHRH injection. Blood samples $(1 \mathrm{ml})$ were obtained by jugular venepuncture under slight ether anaesthesia. Blood samples were centrifuged immediately after each time point, and each rat received its own red blood cells suspended in $0.9 \%$ saline to avoid anaemia. Plasma was stored at $-20^{\circ} \mathrm{C}$ until assayed for $\mathrm{LH}, \mathrm{FSH}$ and prolactin.

\section{Radioimmunoassay of gonadotrophins and prolactin}

Plasma LH, FSH and prolactin concentrations were measured by specific radioimmunoassays using second antibody-facilitated separation and reagents provided by the National Hormone and Pituitary Program (NIADDK, Bethesda, MD). The assays were validated as described by Tresguerres et al. (1981). LH concentrations were expressed as $\mathrm{pg} \mathrm{ml}^{-1}$ in terms of NIADDK rat LH-RP-3. The sensitivity of the assay was $20 \mathrm{pg} \mathrm{LH} \mathrm{ml}{ }^{-1}$. The final dilution of anti-rat LH serum was 1:100 000 . The intra-assay coefficient of variation for the $\mathrm{LH}$ assay was $6 \%$. FSH concentrations were expressed in pg FSH-RP-3 $\mathrm{ml}^{-1}$ and the sensitivity of the assay was $12.5 \mathrm{ng} \mathrm{FSH} \mathrm{ml}^{-1}$. The final dilution of anti-rat FSH 
serum was 1:2000. The intra-assay coefficient of variation for the FSH assay was $9.5 \%$. Prolactin concentrations were expressed as pg rat prolactin RP- $3 \mathrm{ml}^{-1}$ and the sensitivity of the assay was $5 \mathrm{\mu g} \mathrm{l}^{-1}$. The final dilution of anti-rat prolactinS-9 serum was 1:5000. The intra-assay coefficient of variation for the prolactin assay was $7 \%$. All samples were run in the same assay for each hormone to avoid interassay variations.

\section{Radioimmunoassay of oestradiol}

Plasma oestradiol was measured using an ${ }^{125}$ I-labelled radioimmunoassay kit using commercial ImmunoChem ${ }^{\mathrm{TM}}$ coated tubes according to the manufacturer's instructions (ICN Pharmaceuticals, Inc., Costa Mesa, CA). The minimum amount of oestradiol significantly different from 0 was $10 \mathrm{pg} \mathrm{ml}^{-1}$. The maximum binding of the assay was $28.6 \%$ and the intra-assay coefficient of variation was $5.5 \%$.

\section{Statistical analysis}

Data from each age group were adjusted to a normal distribution test before they were used in the statistical analysis. A 99\% accuracy to normal distribution was required. Statistical analysis was performed using the SIGMA statistical program (Copyright Horus Hardware, 1986). Results were

(a)

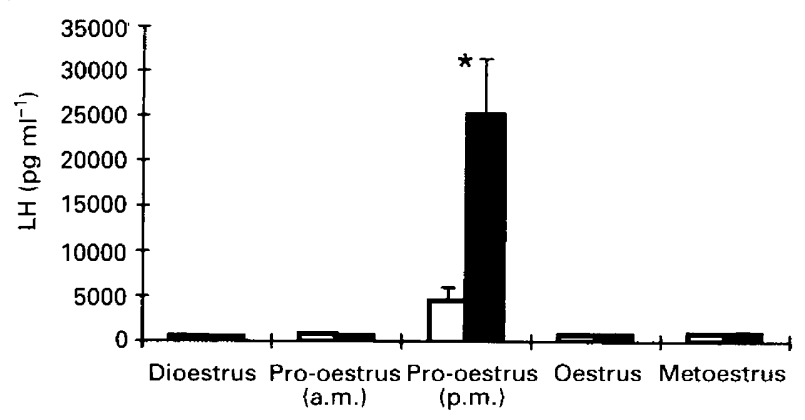

(c)



expressed as mean \pm SEM. Comparisons among groups of data for hormones were determined by one-way ANOVA; individual comparisons were then made by Newman-Keuls multi-range test. $P$ values $<0.05$ were considered significant.

\section{Results}

\section{Hormone concentrations throughout the oestrous cycle}

LH concentrations were low at all stages of the oestrous cycle except in the afternoon of the day of pro-oestrus when an LH surge was observed (Fig. 1). After 11-months-old rats showing irregular duration of the oestrous cycle were treated with melatonin for 2 months, no differences were observed in LH secretion at dioestrus, pro-oestrus p.m., oestrus and metoestrus compared with control animals. However, the LH surge in the afternoon of the day of pro-oestrus was significantly greater $(P<0.01)$ in the melatonin treated group compared with the controls. FSH concentrations were similar in all stages of the oestrous cycle in control rats. After melatonin treatment, the FSH surge in the afternoon of the day of pro-oestrus was significantly greater $(P<0.01)$ compared with that in the control animals. A significant increase in $\mathrm{FSH}$ concentrations $(P<0.05)$ in melatonin treated rats compared with control rats was also observed at pro-oestrus a.m. and oestrus. Melatonin administration for 2 months to 11-month-

(b)

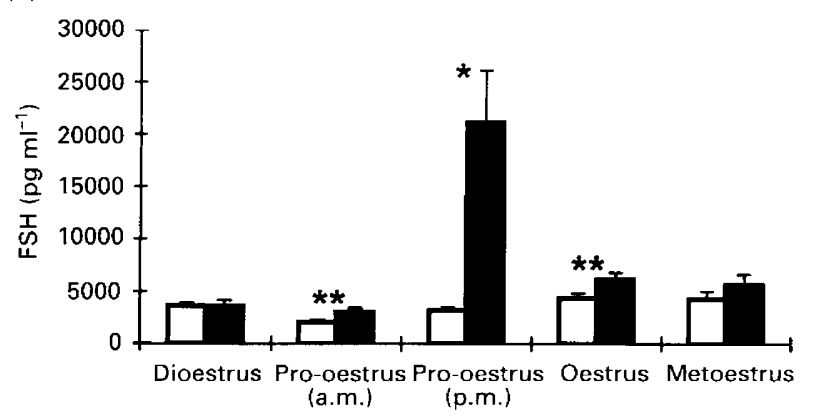

(c)

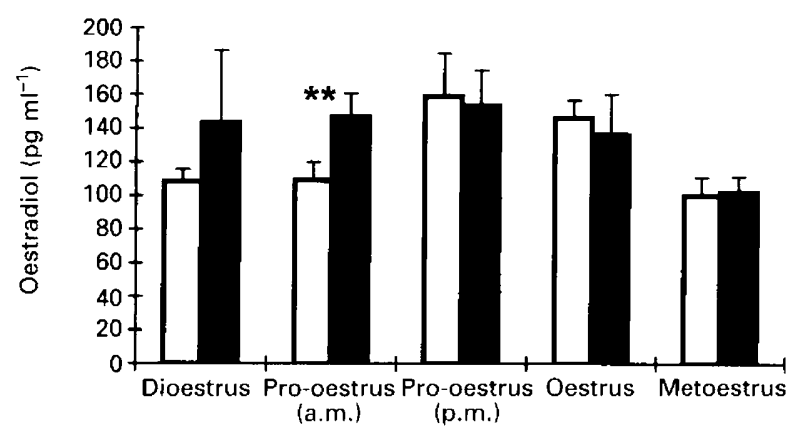

Fig. 1. Concentrations of plasma LH (a), FSH (b), prolactin (c) and oestradiol (d) in all stages of the oestrous cycle in control ( $\square$ ) and melatonin treated (ם) 11- to 13-month-old female rats. Rats were treated with $150 \mu \mathrm{g}$ melatonin per $100 \mathrm{~g}$ body weight for 2 months. ${ }^{*} P<0.01,{ }^{* * P}<0.05$ versus control group. 
old rats produced increased prolactin concentrations in prooestrus (a.m. and p.m.) and oestrus; this increase was significantly higher $(P<0.01)$ in the afternoon of the day of pro-oestrus compared with the control group. Oestradiol concentrations were higher at dioestrus and in the morning of the day of pro-oestrus in rats that received melatonin treatment, although the increase was only significantly higher $(P<0.05)$ in the morning of the day of pro-oestrus compared with the control group. In the afternoon of the day of prooestrus, as well as at oestrus and metoestrus, oestradiol concentrations were similar in both groups.

\section{Hormone concentrations throughout pro-oestrus}

Plasma LH and FSH concentrations on the day of prooestrus in 11- to 15-month-old female rats are shown (Fig. 2). $\mathrm{LH}$ concentrations in the control and treatment group were similar from $07: 00 \mathrm{~h}$ to $14: 00 \mathrm{~h}$, but a significant increase $(P<0.01)$ in $\mathrm{LH}$ was observed at $17: 00 \mathrm{~h}$ in the melatonintreated animals compared with the controls. FSH concentrations during the day of pro-oestrus in control rats
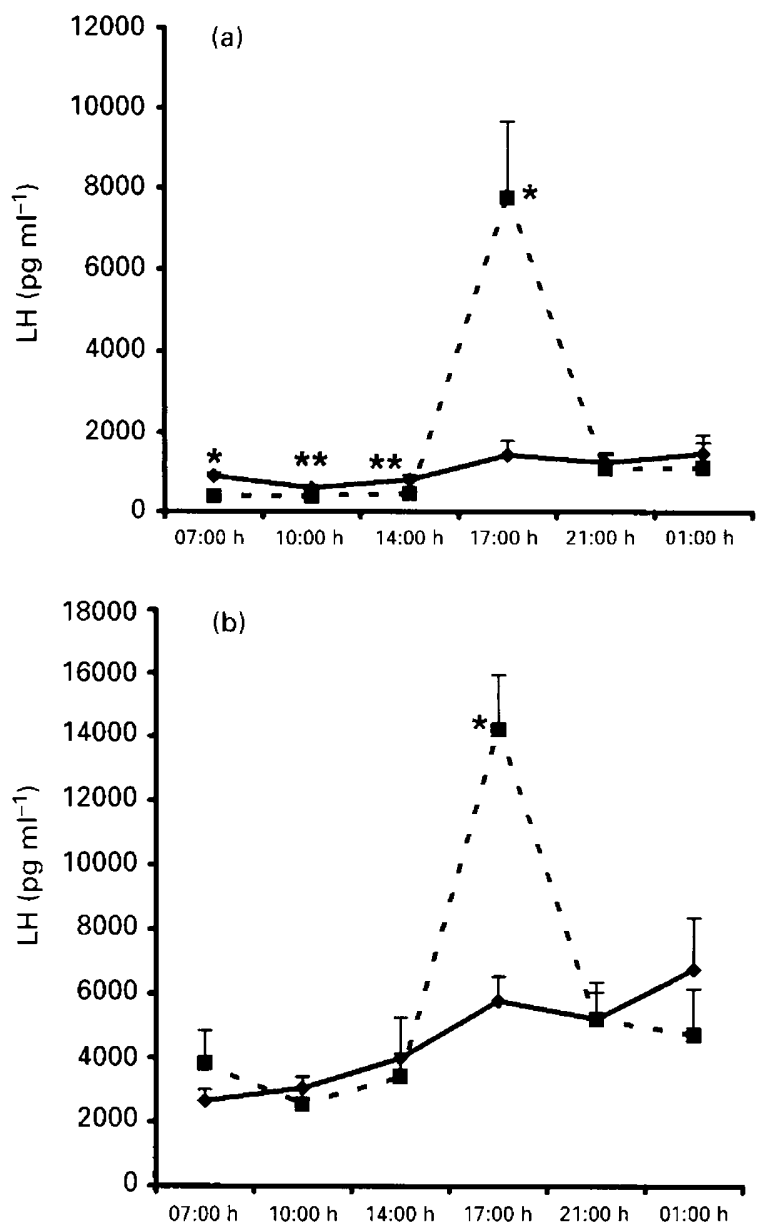

Fig. 2. Concentrations of plasma LH (a) and FSH (b) throughout prooestrus in control (- -) and melatonin treated (--- a---) 11- to 15month-old rats. Rats were treated with $150 \mu \mathrm{g}$ melatonin per $100 \mathrm{~g}$ body weight for 2 months. ${ }^{*}<0.01,{ }^{*} P<0.05$ versus control group. showing irregular duration of the oestrous cycle increased progressively from $07: 00 \mathrm{~h}$ to $01: 00 \mathrm{~h}$, reaching the highest values at $17: 00 \mathrm{~h}$ and $01: 00 \mathrm{~h}$. Melatonin treatment only affected the concentration of FSH at 17:00 h, when significantly increased concentrations were observed $(P<0.01)$ compared with controls.

\section{Pituitary responsiveness to $\mathrm{LHRH}$}

The effects of the administration of $50 \mathrm{ng}$ LHRH to 12month-old female rats are shown (Fig. 3). A positive response in LH secretion was observed $15 \mathrm{~min}$ after injection of LHRH, and this was maintained for $90 \mathrm{~min}$ in both the control and the melatonin treated groups. The magnitude of the response was higher in the melatonin treated group compared with the controls, as significantly higher $(P<0.05)$ LH concentrations were observed 30 and $60 \mathrm{~min}$ after LHRH.
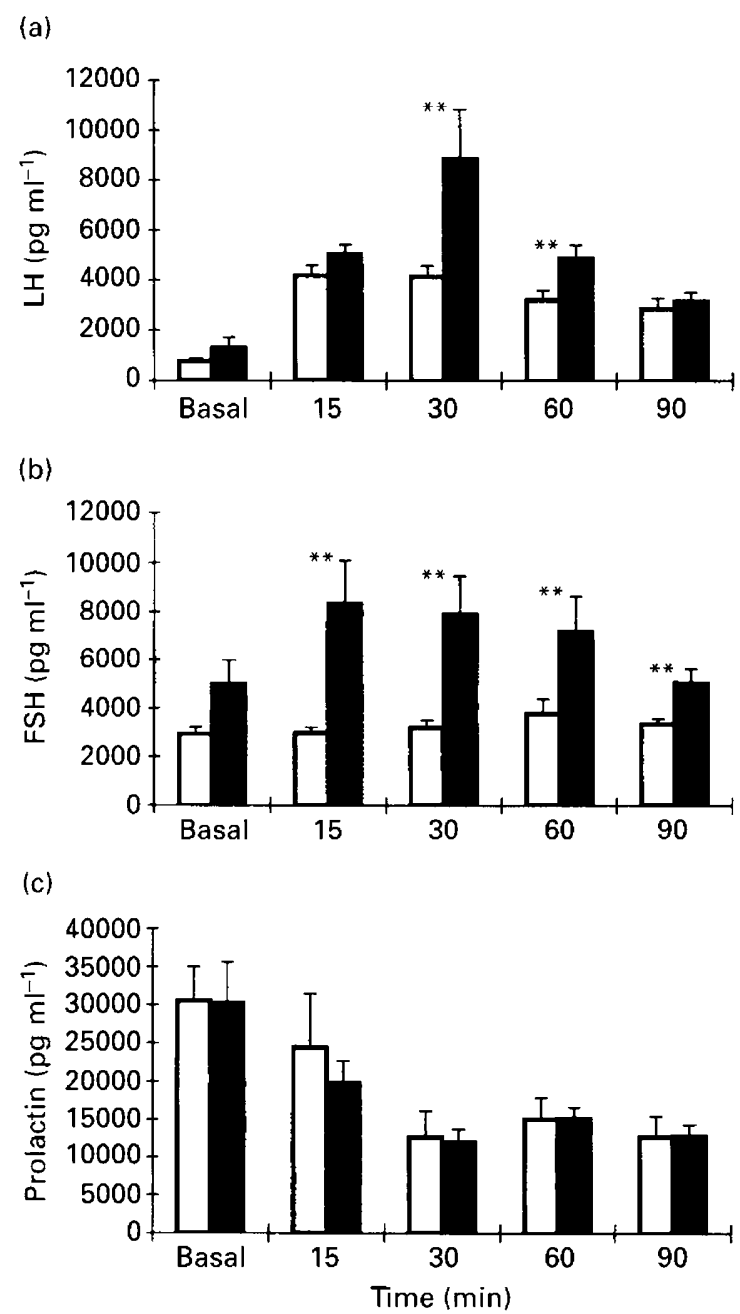

Fig. 3. Concentrations of plasma LH (a), FSH (b) and prolactin (c) at dioestrus after injection of $50 \mathrm{ng}$ LHRH per $100 \mathrm{~g}$ body weight in control $(\square)$ and melatonin treated ( $\square$ ) 12-month-old female rats. Rats were treated with $150 \mu \mathrm{g}$ melatonin per $100 \mathrm{~g}$ body weight for 1 month.

${ }^{*} P<0.05$ versus control group. 
In the control group, FSH secretion showed no response to LHRH. However, a positive response was observed in melatonin-treated rats showing irregular duration of the oestrous cycle: at 15, 30, 60 and 90 min after LHRH and FSH concentrations were significantly $(P<0.05)$ higher in these animals compared with the controls. In melatonin treated rats at $90 \mathrm{~min}$ after injection of LHRH, FSH concentrations decreased to basal concentrations, but remained significantly higher $(P<0.05)$ than in the control group. Prolactin secretion in both groups studied showed a negative response to LHRH and reached the lowest concentration $30 \mathrm{~min}$ after injection of LHRH. No significant differences were observed between the two groups at any time after administration of LHRH.

The percentage distribution of the duration of the oestrous cycle in 11- to 13-month-old female rats, before melatonin treatment, were as follows: $4-5$ days, $0 \% ; 6-10$ days, $23.08 \%$; $>10$ days, $84.61 \%$. After melatonin treatment for 2 months the distribution was as follows: $4-5$ days, $38.46 \% ; 6-10$ days, $23.08 \% ;>10$ days, $38.46 \%$.

\section{Discussion}

Cyclical release of pituitary gonadotrophins and prolactin in female rats is regulated by interactive neuroendocrine mechanisms (Sarkar et al., 1974; Debeljuk et al., 1977). The results of the present study showed increased plasma LH concentrations only on the afternoon of the day of prooestrus in control and melatonin treated rats, as was reported in young female rats with a 4 day oestrous cycle (Sarkar et al., 1974; Parnet et al., 1990). Other studies indicated that the timing of melatonin treatment is critical to produce an inhibitory effect on the LH secretion during pro-oestrus in young cyclic rats (Cardinali, 1974; Sorrentino, 1975; Rivest $e t$ al., 1985). Ying and Greep (1973) found that inhibition of LH secretion was observed when melatonin was administered between $14: 00 \mathrm{~h}$ and $16: 00 \mathrm{~h}$ on the day of pro-oestrus. Chronic melatonin administration delayed sexual maturation of female rats and pro-oestrous surges of gonadotrophins and oestradiol occurred at a reduced frequency (Rivest et al., 1985). However, in the present study on middle-aged female rats, significantly increased LH concentrations were observed in the afternoon of the day of pro-oestrus. A facilitatory role of melatonin on the synchronization of the LH surge was observed in pinealectomized rats. After melatonin treatment in dioestrus during the critical period before the lights were switched off, the individual differences in the timing of the LH surge in pinealectomized rats were reduced (Chiba et al., 1994). The results of the present study indicate that melatonin administration for 2 months also enhanced the amount of $\mathrm{LH}$ released during the surge and may have improved synchronization, since significantly higher LH and FSH concentrations after melatonin treatment were observed only at 17:00 h, while in the control middle-aged animals increased concentrations were observed over a long period of time. Although, the possible physiological implications of the results are important, the mechanisms involved in this process await further study. Harney et al. (1996) reported that the suprachiasmatic nucleus influences the rhythm of gonadotrophin secretion by gonadotrophin releasing hormone (LHRH) neurones; melatonin receptors have been described in the suprachiasmatic nucleus (Vanecek et al., 1987). The results of the present study indicate that melatonin treatment in middle-aged rats, in which melatonin secretion is decreased (Pang et al., 1984), may improve LH as well as FSH secretion through a possible effect on the suprachiasmatic nucleus.

Several studies have indicated that melatonin regulates prolactin secretion (Bispink et al., 1990; Okatani and Sagara, 1993). Administration of melatonin resulted in a marked and rapid decrease of previously high plasma prolactin concentrations observed in pituitary-grafted rats (Esquifino $e t$ al., 1989). In the present experiments in which prolactin concentrations were low, melatonin restored the prolactin peak values during the afternoon of the day of pro-oestrus in middle-aged rats. It is known that the pattern of prolactin secretion during the oestrous cycle in rats is characterized by low concentrations except for a brief period on the afternoon and evening of the day of pro-oestrus (Neill, 1970; Ojeda et al., 1976; Anselmo-Franci et al., 1997). The results of the present study indicate that melatonin has opposing effects depending on whether prolactin concentrations are initially high or low.

Surges in the secretion of LH, FSH and prolactin are preceded and stimulated by the increasing concentrations of follicular oestrogen (Neill et al., 1971; Parnet et al., 1990). The results of the present study indicate that melatonin treatment in middle-aged rats had a positive influence on this mechanism; oestradiol concentrations were increased on the morning of pro-oestrus, which preceded the gonadotrophin and prolactin surges observed in the afternoon of prooestrus. The possibility that melatonin acts directly on the ovary must be considered since melatonin has been detected in human follicular fluid (Brzezinski et al., 1987), and specific melatonin receptors (Cohen et al., 1978) are present in hamster, rat and human ovaries. In addition, direct effects of melatonin on ovarian steroidogenesis in vitro have been reported (Macphee et al., 1975).

The results of the present study showed a stimulatory effect of melatonin on the gonadotrophin response to LHRH, since treated rats showed greater $\mathrm{LH}$ secretion and amplitude of FSH surge than did control rats. Cagnacci et al. (1995) reported a stimulatory effect of melatonin on the gonadotrophin response to physiological or submaximal doses of LHRH during the follicular phase of the menstrual cycle in women. How melatonin augments this pituitary response to LHRH remains unknown. The presence of specific melatonin receptors in the pars tuberalis in rodents (Vanecek et al., 1987; Weaver and Reppert, 1989) and humans (Weaver $e t$ al., 1993) supports a direct effect of melatonin on pituitary cells. However, the effect of melatonin on the hypothalamic nuclei mentioned above, which directly or indirectly influences the pituitary response to LHRH, cannot be disregarded. Among the factors involved in the regulation of prolactin secretion, LHRH may be inhibitory (Esquifino et al., 1989) or stimulatory (Asch et al., 1985; Debeljuk et al., 1985). The results of the present study indicate an inhibitory role of LHRH, since plasma prolactin concentrations decreased $30 \mathrm{~min}$ after LHRH injection. Several studies have indicated that melatonin regulates prolactin secretion 
(Bispink et al., 1990; Okatani and Sagara, 1993). The similarity in the pituitary response to LHRH observed in both groups of middle-aged rats in the present study indicates that exogenous melatonin does not stimulate the lactotroph response to LHRH during dioestrus.

Aschheim (1976) reported that in 12 month-old Wistar rats, $60 \%$ showed normal oestrous cycles, $20 \%$ showed persistent oestrus and $20 \%$ showed repetitive pseudopregnancies, which is indicative of reduced activity of the hypothalamic-pituitary-ovarian axis during ageing (Arias et al., 1996; Fujimoto et al., 1996). It is well documented that melatonin administration to young female rats suppresses the functional activity of the ovary (Tamarkin et al., 1976). However, the results of the present study indicate that melatonin treatment during ageing has an opposite role on gonadotrophins and prolactin, since oestrous cyclicity was improved. Whatever the mechanism, these results indicate a facilitatory role of melatonin on the hypothalamicpituitary-ovarian axis in middle-aged rats showing irregular duration of the oestrous cycle.

The authors wish to express their gratitude to the NIADDK, NHPP and A. F. Parlow for the provisions of radioimmunoassay materials for LH, FSH and prolactin radioimmunoassays. This work has been supported for the Spanish Ministry of Health, Fondo de Investigación Sanitaria; FIS N ${ }^{\circ}$ 97/0988.

\section{References}

Anselmo-Franci JA, Franci CR, Krulich L, Antunes-Rodrigues $J$ and McCann SM (1997) Locus coeruleus lesions decrease norepinephrine input into the medial preoptic area and medial basal hypothalamus and block the LH, FSH and prolactin preovulatory surge Brain Research 767 289-296

Arias $\mathbf{P}$, Carbone S, Szwarcfarb B, Feleder $C$, Rodríguez $M$, Scacchi $\mathbf{P}$ and Moguilevsky JA (1996) Effects of aging on N-methyl-D-aspartate (NMDA)induced GnRH and LH release in female rats Brain Research 740 234-238

Asch RH, Rojas FJ, Bartke A, Schally AV, Tice TR, Klemcke HG, Siler-Khodr TM, Bray RE and Hogan MP (1985) Prolonged suppression of plasma LH levels in male after a single injection of an LH-RH agonist in poly (D,Llactide-co-glycolide) microcapsules Journal of Andrology 6 83-88

Aschheim P (1976) Aging in the hypothalamic-hypophyseal ovarian axis in the rat. In Hypothalamus Pituitary and Aging Pp 376-418 Eds AV Everitt and JA Burgess. Springfield, Illinois

Berga SL, Mortola JF and Yen SSC (1988) Amplification of nocturnal melatonin secretion in women with functional hypothalamic amenorrohea Journal of Clinical Endocrinology and Metabolism 66 242-244

Bispink G, Zimmermann R, Weise HC and Leidenberg F (1990) Influence of melatonin on the sleep-independent component of prolactin secretion journal of Pineal Research 8 97-106

Brzezinski A, Seibel MM, Lynch HJ, Deng M-H and Wurtman RJ (1987) Melatonin in human preovulatory follicular fluid Journat of Clinical Endocrinology and Metabolism 64 865-867

Cagnacci A, Paoletti AM, Soldani R, Orru M, Maschio E and Melis GB (1995) Melatonin enhances the luteinizing hormone and follicle-stimulating hormone responses to gonadotrophin-releasing hormone in the follicular, but not in the luteal, menstrual phase Journal of Clinical Endocrinology and Metabolism 80 1095-1099

Cardinali DP (1974) Melatonin and the endocrine role of the pineal organ. In Current Topics in Experimental Endocrinology pp 107-128 Eds VHT James and L Martini. Academic Press, New York

Chiba A, Akema T and Toyoda JI (1994) Effects of pinealectomy and melatonin on the timing of the proestrus luteinizing hormone surge in the rat Neuroendocrinology 59 163-168

Cohen M, Roselle D and Chabner B (1978) Evidence for a cytoplasmic melatonin receptor Nature 274 894-895

Debeljuk L, Rettori V and Rozados R (1977) Pituitary LH levels and response to LHRH in female rats pretreated with oestradiol Journal of Reproduction and Fertility 51 127-129

Debeljuk L, Torres-Alemán I and Schally AV (1985) Antiserum to LH-RH blocks haloperidol-induced hiperprolactinemia in female rats Neuroendocrinology 40 185-187

Esquifino AI, Villanua MA, Agrasal C, Reiter RJ and Tresguerres JAF (1989) Melatonin effects on prolactin secretion in pituitary-grafted female rats Journal of Endocrinologic Investigation 12 171-176

Fujimoto VY, Klein NA, Battaglia DE, Bremner WJ and Soules MR (1996) The anterior pituitary response to a gonadotrophin-releasing hormone challenge test in normal older reproductive-age women Fertility and Sterility $65539-544$

Harney JP, Scarbrough K, Rosewell KL and Wise PM (1996) In vivo antisense antagonism of vasoactive intestinal peptide in the suprachiasmatic nuclei causes aging-like changes in the oestradiol-induced luteinizing hormone and prolactin Endocrinology 137 3696-3701

Kauppila A, Kivela A, Pakarinen A and Vakkuri O (1987) Inverse relationship between melatonin and ovarian activity in humans in a region with a strong seasonal contrast in luminosity Journal of Clinical Endocrinology and Metabolism 65 823-828

Lambalk CB, de Boer L, Schoute E, Popp-Snyders C and Schoemaker J (1997) Postmenopausal and chronological age have divergent effects on pituitary and hypothalamic function in episodic gonadotrophin secretion Clinical Endocrinology 46 439-443

Laughlin GA, Loucks AB and Yen SSC (1991) Marked augmentation of nocturnal melatonin secretion in amenorrheic athletes, but not cycling athletes: unaltered by opioidergic blockade Journal of Clinical Endocrinology and Metabolism 73 1321-1326

MacPhee A, Cole EE and Rice BF (1975) The effect of melatonin on steroidogenesis by the human ovary in vitro. Journal of Clinical Endocrinology and Metabolism 40 688-696

Neill JD (1970) Effects of stress on serum prolactin and luteinizing hormone levels during the oestrous cycle of the rat Endocrinology 87 1192-1197

Neill JD, Freeman ME and Tilson SA (1971) Control of the proestrous surge of prolactin and luteinizing hormone secretion by estrogens in the rat Endocrinology 89 1448-1453

Oaknin-Bendahan S, Anis Y, Nir I and Zisapel N (1995) Effects of long-term administration of melatonin and a putative antagonist on ageing rats NeuroReport 6 785-788

Ojeda SR, Krulich L and Jameson HE (1976) Developmental pattern of plasma and pituitary TSH and prolactin and hypothalamic TRH in the female rat Endocrine Research 3 387-406

Okatani $Y$ and Sagara $Y$ (1993) Role of melatonin in nocturnal prolactin secretion in women with normoprolactinemia and mild hyperprolactinemia American Journal of Obstetrics and Gynecology 168 854-861

Pang SF, Tang F and Tang PL (1984) Negative correlation of age and the levels of pineal melatonin, pineal $\mathrm{N}$-acetylserotonin, and serum melatonin in male rats Journal of Experimental Zoology 229 41-47

Parnet P, Lenoir V, Palkovits M and Kerdelhue B (1990) Oestrous cycle variations in gonadotrophin-releasing hormone, substance $P$ and betaendorphin contents in the median eminence, the arcuate nucleus and the medial preoptic nucleus in the rat. A detailed analysis of proestrous changes Journal of Neuroendocrinology 2291-296

Reiter RJ (1992) The aging pineal gland and its physiological consequences Bioassays 14 167-175

Reiter RJ (1994) Pineal function during aging: attenuation of the melatonin rhythm and its neurobiological consequences Acta Neurobiological Experimental 54 31-39

Rivest RW, Lang U, Aubert ML and Sizonenko PC (1985) Daily administration of melatonin delays rat vaginal opening and disrupts the first oestrous cycle: evidence that these effects are synchronized by the onset of light Endocrinology 116 779-787

Sarkar DK, Chiappa SA, Fink G and Sherwood N (1974) Gonadotrophin releasing hormone surge in the proestrous rat Nature 264 461-463

Sorrentino S, Jr (1975) Ovulation in PMS-treated rats with gonadotrophin releasing hormone after pentobarbital and melatonin block Neuroendocrinology 19 1534-1541

Tamarkin L, Westrom WK, Hamill AI and Goldman BD (1976) Effect of melatonin on the reproductive system of male and female Syrian hamsters: a diurnal rhythm in sensitivity to melatonin Endocrinology 99 1534-1541

Tresguerres JAF, Esquifino AI, Pérez Méndez LF and López Calderón A (1981) Possible role of prolactin in the inhibitory effect of oestradiol on the hypothalamic-pituitary-testicular axis in the rat Endocrinology 108 83-87 
Vanecek J, Paulik A and Illnerova H (1987) Hypothalamic melatonin receptor sites revealed by autoradiography Brain Research 435 359-362

Voordouw BCG, Euser R, Verdonk RER, Alberda BTh, de Jong FH, Drogendijk AC, Fauser BCJM and Cohe M (1992) Melatonin and melatonin-progestin combination alter pituitary-ovarian function in women and can inhibit ovulation Journal of Clinical Endocrinology and Metabolism 74 108-117

Weaver DR and Reppert SM (1989) Melatonin receptors are present in the ferret pars tuberalis and pars distalis, but not in brain Endocrinology 45 955-965

Weaver DR, Stehle JH, Stopa EG and Reppert SM (1993) Melatonin receptors in human hypothalamus and pituitary: implications for circadian and reproduction responses to melatonin journal of Clinical Endocrinology and Metabolism 76 295-301

Ying S-Y and Greep RO (1973) Inhibition of ovulation by melatonin in the cyclic rat Endocrinology 92 333-336 